\title{
Laparoscopic Management of Polypoidal Lesions of the Stomach
}

\author{
Shantata J Kudchadkar ${ }^{1}$, Pranav Mandovra², Roy Patankar ${ }^{3}$
}

\begin{abstract}
Aim: Our aim was to study the feasibility of a laparoscopic approach in the management of polypoidal lesions of the stomach.

Materials and methods: We present a review of laparoscopic management in polypoidal lesions of the stomach in four patients. All patients underwent routine preoperative workup along with esophagogastroduodenoscopy, biopsy, and contrast-enhanced computed tomography (CECT) scan of the abdomen. Three patients underwent wedge resection of the stomach using a laparoscopic linear stapler and one underwent laparoscopic anterior wall gastrotomy with polypectomy.

Results: Of four patients, three were males and one was female in the age range of 40-60 years. Presenting symptoms ranged from generalized weakness, episodes of intermittent vomiting, dyspepsia, and weight loss. Common sites involved were fundus and body of the stomach in three patients and antrum in one patient. Surgery via a laparoscopic approach was the mainstay of the treatment. Final histopathology revealed gastrointestinal stromal tumor (GIST) in three patients and adenomatous polyp in one patient. Patients diagnosed with GIST were further referred to a medical oncologist for mutational analysis and adjuvant therapy. All patients are on regular follow-up postoperatively.

Conclusion: Asymptomatic, polypoidal lesions of the stomach can present with occult Gl bleeding or gastric outlet obstruction. The main point to be taken into consideration in treating large-sized polyps is the selection of management option (endoscopic vs laparoscopic). Laparoscopic excision is a better alternative to treat giant polyps considering the size, location, and potential for malignancy, as opposed to an endoscopic approach.

Keywords: Adenomatous polyp, Gastric outlet obstruction, Gastric polyp, Gastrointestinal stromal tumor, Hyperplastic polyp, Laparoscopic anterior wall gastrotomy.

World Journal of Laparoscopic Surgery (2018): 10.5005/jp-journals-10033-1346
\end{abstract}

\section{INTRODUCTION}

Polypoidal lesions of the stomach are broadly defined as locally elevated lesions protruding into the gastric lumen, a heterogeneous group of epithelial and subepithelial lesions that vary in histology, neoplastic potential, and management, usually small and asymptomatic (>90\%). Symptoms produced by polypoidal lesions are vague and nonexistent until complications arise such as bleeding, anemia, obstruction, or abdominal pain. ${ }^{1}$ They are discovered incidentally on endoscopic examination in about $2-5 \%{ }^{2}$ The frequency of polyps is increasing with the widespread use of endoscopy for diagnosis and treatment.

Epithelial polyps (hyperplastic, fundic gland, and adenomatous) are the classic gastric polyps, but clusters of endocrine cells (carcinoids), infiltrates (xanthomasand lymphoid proliferations), or mesenchymal proliferations [GIST, leiomyoma, and inflammatory fibroid polyps (IFPs)] may create a mucosal protrusion. ${ }^{3}$

Symptomatology depends upon the size, multiplicity, location, and character of the lesions. Meticulous endoscopic examination, accurate biopsy, histopathologic evaluation, and periodic follow-up examinations are critical.

\section{Materials and Methods}

We present a review of laparoscopic management of four cases of polypoidal lesions of the stomach who presented in our center from December 2017 to December 2018. All patients underwent routine preoperative workup along with upper GI endoscopy and a CECT scan. Three patients underwent wedge resection of the

\begin{abstract}
${ }^{1-3}$ Department of Minimal Access and GI Surgery, Zen Multispeciality Hospital, Mumbai, Maharashtra, India

Corresponding Author: Shantata J Kudchadkar, Department of Minimal Access and GI Surgery, Zen Multispeciality Hospital, Mumbai, Maharashtra, India, Phone: +44 7587437988, e-mail: shantatak@gmail.com

How to cite this article: Kudchadkar SJ, Mandovra P, et al. Laparoscopic Management of Polypoidal Lesions of the Stomach. World J Lap Surg 2018;11(3):111-114.

Source of support: Nil

Conflict of interest: None
\end{abstract}

stomach using a laparoscopic linear stapler and one underwent laparoscopic anterior wall gastrotomy with polypectomy under general anesthesia. Workup and management of all four patients are depicted in Table 1.

\section{SuRgical TechNique}

Port positions and basic steps:

Laparoscopic wedge resection of the stomach using linear staplers (three patients):

- Ports: $10 \mathrm{~mm}$ umbilicus (camera), $12 \mathrm{~mm}$ (working) left midclavicular, two $5 \mathrm{~mm}$ in both anterior axillary lines (working and for traction). Pneumoperitoneum created using open insertion technique and pressure maintained at $12 \mathrm{~mm} \mathrm{Hg}$.

- After identifying lesser sac and greater curvature, short gastric vessels were divided with harmonic. Intraluminal tumor

() The Author(s). 2018 Open Access This article is distributed under the terms of the Creative Commons Attribution 4.0 International License (https://creativecommons. org/licenses/by-nc/4.0/), which permits unrestricted use, distribution, and non-commercial reproduction in any medium, provided you give appropriate credit to the original author(s) and the source, provide a link to the Creative Commons license, and indicate if changes were made. The Creative Commons Public Domain Dedication waiver (http://creativecommons.org/publicdomain/zero/1.0/) applies to the data made available in this article, unless otherwise stated. 
Table 1: Workup and management in our four patients

\begin{tabular}{|c|c|c|c|}
\hline & Workup & In three patients $(2 M, 1 F)$ & In one patient (1M) \\
\hline 1 & $\begin{array}{l}\text { OGD scopy findings } \\
\text { (Fig. 1) }\end{array}$ & $\begin{array}{l}3-3.5,4 \text {, and } 4.5 \mathrm{~cm} \text { single sessile polyp arising } \\
\text { from the fundus and proximal body near } \\
\text { greater curvature of the stomach in three patients } \\
\text { respectively }\end{array}$ & $\begin{array}{l}\text { Large, single, mobile, pendunculated polyp in } \\
\text { antrum with thick stalk in mid-body, prolapsing into } \\
\text { part } 1 \text { of duodenum causing intermittent gastric outlet } \\
\text { obstruction, with solid food residue in fundus and body }\end{array}$ \\
\hline 2 & Biopsy report & Gastric submucosal lesion? GIST in all three patients & Tubulovillous type of adenomatous polyp \\
\hline 3 & CT scan findings (Fig. 2) & $\begin{array}{l}\text { Single, soft tissue attenuating lesion of respec- } \\
\text { tive dimensions arising in fundus and proximal } \\
\text { body near greater curvature of the stomach } \\
\text { with no evidence of LNs or surrounding tissue } \\
\text { involvement }\end{array}$ & $\begin{array}{l}\text { An enhancing polypoidal mass in the gastric antrum, } \\
\text { extending and prolapsing into the proximal duode- } \\
\text { num, } 7.8 \times 4 \mathrm{~cm} \text {, without calcifications, necrosis within. } \\
\text { Adjoining fat planes well maintained with no evidence } \\
\text { of perigastric adenopathy. The stomach distended with } \\
\text { food residue }\end{array}$ \\
\hline 4 & $\begin{array}{l}\text { Surgical procedure } \\
\text { undertaken }\end{array}$ & $\begin{array}{l}\text { Laparoscopic wedge resection of the stomach } \\
\text { using linear stapler }\end{array}$ & $\begin{array}{l}\text { Laparoscopic anterior wall gastrotomy with } \\
\text { polypectomy }\end{array}$ \\
\hline 5 & $\begin{array}{l}\text { Final histopathological } \\
\text { examination (HPE) } \\
\text { report }\end{array}$ & Gastric GIST in all three patients & $\begin{array}{l}\text { Adenomatous polyp with no evidence of malignancy } \\
\text { (Fig. 3) }\end{array}$ \\
\hline
\end{tabular}
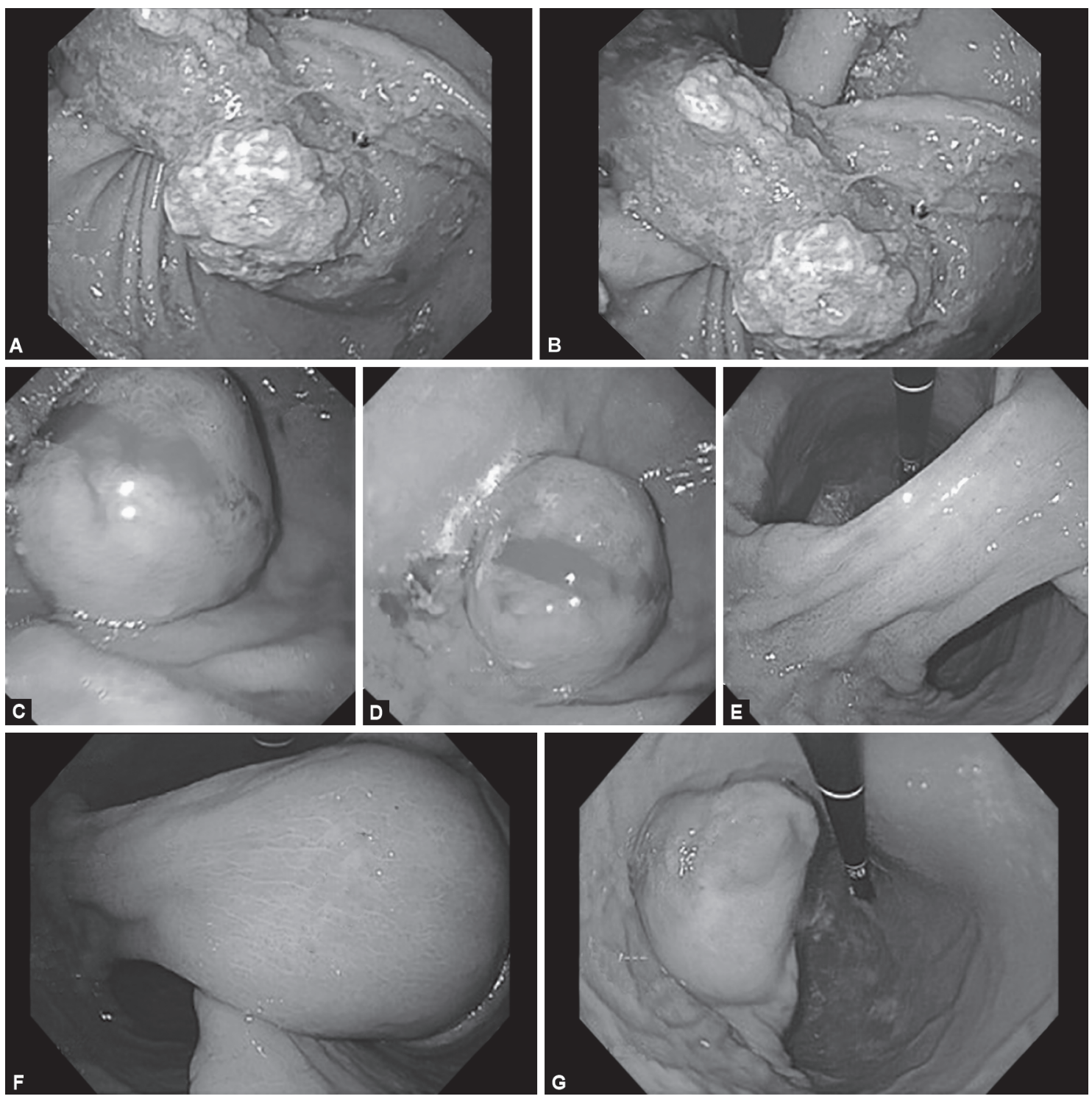

Figs 1 A to G: Preoperative esophagogastroduodenoscopy (OGD scopy) pictures 

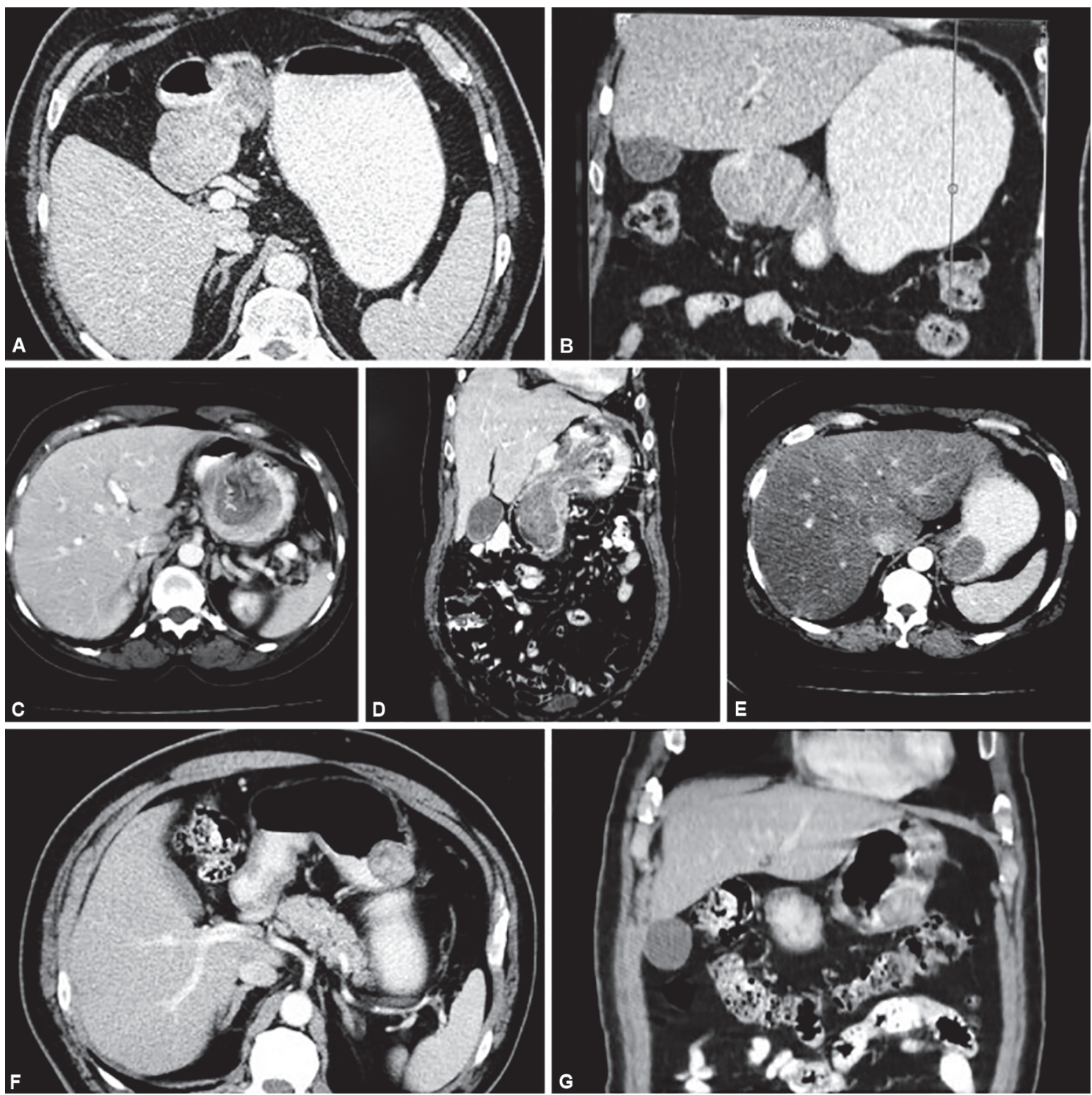

Figs $2 \mathrm{~A}$ to $\mathrm{G}$ : Computed tomography (CT) images

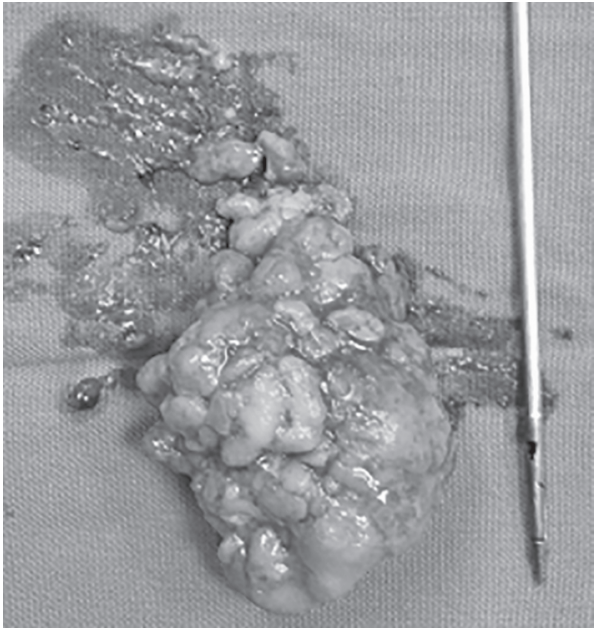

Fig. 3: Adenomatous polyp (operative specimen) identified on posterior wall along the greater curvature. Intraoperatively, upper GI endoscopy was done to ensure adequate margins all around the tumor.

- Wedge resection done using three staplers (2 purple 60, 1 blue 45 ) and suture line further reinforced with mersilk 3-0. Specimen was delivered under direct vision via minilaparotomy incision.

Laparoscopic anterior wall gastrotomy with polypectomy (one patient):

- Ports: $10 \mathrm{~mm}$ umbilicus (camera), $12 \mathrm{~mm}$ (working) left midclavicular in line with umbilicus, two $10 \mathrm{~mm}$ in both subcostal regions (working and for traction). Pneumoperitoneum created using open insertion technique and pressure maintained at $12 \mathrm{~mm} \mathrm{Hg}$.

- Fundus and greater curvature freed by dividing short gastric vessels with thunder beat. Anterior wall of the stomach opened in mid-body close to the attachment of tumor between two silk stay sutures. $7 \times 4 \mathrm{~cm}$ pedunculated polyp everted out 
and resected with adequate margins by firing linear staplers at pedicle base in the body of the stomach. Reinforcement vicryl sutures placed around the staple line.

- Ryle's tube (RT) position was confirmed and gastrotomy closed in two layers with continuous ethibond and silk sutures. Specimen was delivered under direct vision by increasing left $12 \mathrm{~mm}$ port.

In all cases, hemostasis was confirmed at the end of the procedure, and the 10 and $12 \mathrm{~mm}$ ports closed under direct vision.

\section{Results}

Of the four patients, three were males and one was female in the age group of 40-60 years. Presenting symptoms in all ranged from generalised weakness, episodes of intermittent vomiting, dyspepsia, and weight loss. Common sites involved were fundus and the body of the stomach in three patients and antrum in one patient.

Table 1 gives the details regarding esophagogastroduodenoscopy (OGD scopy), biopsy, CT scan findings, surgical procedure undertaken, and final histopathological diagnosis in our four patients. Postoperatively, our patients received IV antibiotic and PPI for 5 days. All had good postop recovery with uneventful course and were discharged on soft diet by day 8 .

Histopathologic slides were evaluated by the same pathologist and patients are on regular follow-up with yearly check upper $\mathrm{Gl}$ endoscopy. Patients with GIST were referred to a medical oncologist for mutational study and adjuvant therapy.

\section{Discussion}

Giant polypoidal lesions of the stomach are uncommon, and detection of polyps at upper gastrointestinal endoscopy is usually an incidental occurrence (2-5\%). ${ }^{4}$ Research reports showed that the polyps occurred equally in males and females and that two-thirds occurred in the age group above 60 years. ${ }^{5}$

Histologically, they are classified as hyperplastic,inflammatory, adenomatous, and fundic gland polyps. Hyperplastic polyps are the most common, accounting for $85-90 \%$ of all cases. Adenomas account for only $5-10 \%$, and less than $1 \%$ of these lesions are reported to have malignant changes. ${ }^{6}$ While gastric polyps are commonly asymptomatic, they can cause dyspepsia, epigastric pain, or present with complications such as bleeding due toulceration, anemia, and gastric outlet obstruction.

Rate of malignant transformation depends on size and histology. Fundic gland and IFPs have virtually no malignant potential. The risk of malignancy has been reported to be $0-8.6 \%$ (mean $2.1 \%$ ) for hyperplastic polyps, approximately $5 \%$ for tubular adenomas and $28.5-40 \%$ for villous adenomas. So definite histopathological diagnosis is vital and mandatory. ${ }^{7}$

Gastrointestinal stromal tumors are rare tumors of the digestive tract, with an incidence of about 1.5 per 100,000/year (50-60\% in the stomach). The average age of occurrence is $60-65$ years with equal gender distribution. Majority are CD117 positive, but $5 \%$ are negative and diagnosis is confirmed by immunohistochemistry tests that identify CD117 or DOG1. They arise from interstitial cells described by Cajal and are characterized by mutations of C-KIT and PDGFRA genes which help in precise diagnosis and targeted treatment.
Surgical resection is the mainstay for nonmetastatic tumors, most commonly in the form of a wedge resection. Treatment of GIST requires a multidisciplinary team approach consisting of pathologist, radiologist, surgeon, and oncologist. ${ }^{8}$

Basic treatment of polypoidal lesions of the stomach is excision, either endoscopic or surgical. Surgical treatment is recommended in polyps greater than $2 \mathrm{~cm}$, sessile polyps, and failure of endoscopic treatment. ${ }^{9}$ Incidence of gastric outlet obstruction due to polyps is unknown, with only few cases reported in the literature. ${ }^{10}$

\section{Conclusion}

Though rare in occurrence and majority being asymptomatic, polypoidal lesions of the stomach can present with anemia, occult GI bleeding, or gastric outlet obstruction. We presented a review of four cases of polypoidal lesions of the stomach with special attention toward their management via a laparoscopic approach. The main point to be taken into consideration in treating large-sized polyps is the selection of management option (endoscopic or laparoscopic). Because of their malignant potential, histopathological evaluation is mandatory.

The main disadvantage of endoscopic methods is the risk of incomplete tumor resection. Also, the procedure becomes difficult with an increase in polyp diameter and complications such as bleeding and perforationmay occur.

So, it seems that laparoscopic excision is a better alternative to treat such polyps, considering the size, location, and potential for malignancy, as opposed to an endoscopic approach.

\section{References}

1. Al-Haddad M, Ward EM, et al. Hyperplastic polyps of the gastric antrum in patients with gastrointestinal blood loss. Dig Dis Sci 2007;52(1):105-109. DOI: 10.1007/s10620-006-9182-5.

2. Dekker W. Clinical relevance of gastric and duodenal polyps. Scand J Gastroenterol Suppl 1990;25(Suppl 178):7-12. DOI: 10.3109/ 00365529009093144.

3. Carmack SW, Genta RM, et al. Management of gastric polyps: a pathology-based guide for gastroenterologists. Nat Rev Gastroenterol Hepatol 2009;6(6):331-341. DOI: 10.1038/nrgastro.2009.70.

4. Morais DJ, Yamanaka A, et al. Gastric polyps: a retrospective analysis of 26,000 digestive endoscopies. Arq Gastroenterol 2007;44(1):14-17. DOI: 10.1590/S0004-28032007000100004.

5. Archimandritis A, Spiliadis C, et al. Gastric epithelial polyps: a retrospective endoscopic study of 12974 symptomatic patients. Ital J Gastroenterol 1996;28(7):387-390.

6. Palacios Salas F, Frisancho Velarde O, et al. Gastric polyps and histological changes in surrounding mucosa. Rev Gastroenterol Peru 2003;23(4):245-253.

7. Ginsberg GG, Al-Kawas FH, et al. Gastric polyps: relationship of size and histology to cancer risk. Am J Gastroenterol April 1996;91(4): 714-717.

8. Rubin BP, Heinrich MC, et al. Gastrointestinal stromal tumour. The Lancet 2007;369(9574):1731-1741. DOI: 10.1016/S0140-6736(07)60780-6.

9. Sung HY, Cheung DY, et al. Polyps in the gastrointestinal tract: discrepancy between endoscopic forceps biopsies and resected specimens. Eur J Gastroen Hepat 2009;21(2):190-195. DOI: 10.1097/ MEG.0b013e3283140ebd.

10. Jung JT. Gastric polyps and protruding type gastric cancer. Clin Endosc 2013;46(3):243-247. DOI: 10.5946/ce.2013.46.3.243. 